\title{
Discounted Cash Flow Model 2.0
}

\author{
Patrice Gélinas \\ School of Administrative Studies, Faculty of Liberal Arts \& Professional \\ Studies, York University, Toronto, Canada \\ Email: gelinas@yorku.ca
}

Received October 28, 2013; revised November 25, 2013; accepted December 2, 2013

Copyright (C) 2013 Patrice Gélinas. This is an open access article distributed under the Creative Commons Attribution License, which permits unrestricted use, distribution, and reproduction in any medium, provided the original work is properly cited. In accordance of the Creative Commons Attribution License all Copyrights (C) 2013 are reserved for SCIRP and the owner of the intellectual property Patrice Gélinas. All Copyright (C) 2013 are guarded by low and by SCIRP as a guardian.

\begin{abstract}
Unexpected takeover premiums could be due to the limitations of traditional discounted cash flow models that do not take into account the synergetic potential of the valued assets, which should be acquired by another firm. The author offers a method to value a firm taking into account potential value sitting outside the firm due to synergetic potential. The magnitude of this value depends on the scale of potential synergies, on the willingness of third parties to acquire the firm and the post-acquisition use of the assets.
\end{abstract}

Keywords: Financial Analysis; Asset Valuation Theory; Mathematical Finance; Synergies; Net Present Value; Probabilistic Model

\section{Introduction}

Investors are regularly surprised by the takeover premiums that acquirers offer to gain control over the net assets of a target firm. Takeover premiums are puzzling to interpret using efficient market arguments. They also suggest that financial analysts rely on flawed or incomplete valuation assumptions while using one of the several variations of the traditional discounted cash flow (DCF) valuation model $^{1}$ :

$$
\text { Value }=\sum_{i} \frac{\mathrm{CF}_{t+i}}{(1+r)^{i}}
$$

In the equation, $r$ corresponds to the risk-adjusted required rate of return and $i$ indicates the number of years until cash flows (CF) will be earned or released after valuation time $t$. Dividends, accounting earnings and "free cash flows" are three widely used alternative CF measures that analysts select depending on whether they wish to value the firm's equity or the firm's debt plus equity $^{2}$.

An implicit assumption of the traditional DCF model is that the assets will be used optimally by the firm being valued. This assumption can lead to undervaluation be-

\footnotetext{
${ }^{1}$ For a review, see [1] Fernandez (2007).
}

${ }^{2}$ For example, see chapter 19 in [2] White et al. (2003). cause it ignores the possibility that the net assets being analyzed may have the potential to generate greater future cash flows if merged into the operations of another firm. Indeed, potential synergies are often the main arguments that acquirers put forth to justify takeovers to their own shareholders.

We consequently suggest revisiting the traditional DCF valuation model in a 2.0 version that includes the synergetic potential of the assets being analyzed when estimating future cash flow streams. Synergies can come from two main sources. As stated before, the first is the potential for greater projected net future cash flows when assets are merged into an acquirer's pre-acquisition assets. The second source of synergies stems from the potential ability to use a lower discount rate to calculate the present value of future cash flows if a merger makes the assets less risky i.e., less likely to become obsolete.

\section{Certainty of Acquisition}

When assets or operations are integrated in those of the acquiring entity to produce cash flows, it is possible that they subsequently become impossible to resell to another potential acquirer. In that case, if it is certain that potential acquirers will acquire the target firm when it is profitable for them to do so, then the DCF Model 2.0 value of the firm is: 


$$
\text { Value }^{2.0}=\max _{k}\left[\sum_{i} \frac{\mathrm{CF}_{t+i}^{k}}{\left(1+r_{k}\right)^{i}}\right]
$$

In the equation, $k$ indicates the stand-alone firm being valued as well as each of its potential acquirers. For potential acquirers, $\mathrm{CF}$ indicates net incremental cash flows which are discounted at a rate $r$ consistent with the potential acquirer's business conditions.

In a case where the stand-alone firm being valued could be sold to a third party or spun off after being acquired, the DCF Model 2.0 value of the firm is:

$$
\text { Value }^{2.0}=\sum_{i} \max _{k}\left[\frac{\mathrm{CF}_{t+i}^{k}}{\left(1+r_{k}\right)^{i}}\right]
$$

This latter case is analogous to a situation where the assets of the firm can be operated by current owners or leased by the owners of a possibly different acquirer during each future time period.

\section{Uncertain Acquisition}

When it is uncertain that potential acquirers will take over the target firm even if it were profitable for them to so and when the acquired firm would be impossible to resell following a post-acquisition integration, the DCF Model 2.0 expected value of the firm is:

$$
\begin{aligned}
& \text { Value }^{2.0} \\
& =\max _{k}\left[P\left[A_{t}^{k}\right] \sum_{i} \frac{\mathrm{CF}_{t+i}^{k}}{\left(1+r_{k}\right)^{i}}+\left(1-P\left[A_{t}^{k}\right]\right) \sum_{i} \frac{\mathrm{CF}_{t+i}^{t g t}}{\left(1+r_{t g t}\right)^{i}}\right]
\end{aligned}
$$

In the equation, $P[A]$ indicates the probability at valuation time $t$ that the target firm (tgt) being valued will be acquired by potential acquirer $k$ if it is profitable to do so. Equation (2) corresponds to the case of Equation (4) where all probabilities are equal to 1 .

In a case where the stand-alone firm being valued could be sold to a third party or spun off after being acquired, the DCF Model 2.0 expected value of the firm is:

$$
\begin{aligned}
& \text { Value }^{2.0} \\
& =\sum_{i} \max _{k}\left[P\left[A_{t+i}^{k}\right] \frac{\mathrm{CF}_{t+i}^{k}}{\left(1+r_{k}\right)^{i}}+\left(1-P\left[A_{t+i}^{k}\right]\right) \frac{\mathrm{CF}_{t+i}^{t g t}}{\left(1+r_{t g t}\right)^{i}}\right]
\end{aligned}
$$

In the equation, probabilities of acquisition (conditional upon acquisition being expectedly profitable) must be determined for each future period and, for simplicity, they are assumed to be independently distributed. It is also assumed for simplicity that the costs of a spin off or a sale to a third party acquirer are the same. Equation (3) corresponds to the case of Equation (5) where all probabilities are equal to 1 .

Estimating future cash flows that a set of assets could produce should they be merged with the assets of another firm is akin to the work performed by financial analysts supporting managers whose investment strategy is to assemble portfolios of firms they perceived as plausible candidates for "at premium" takeovers. The market inefficiencies these investors exploit would likely shrink with the adoption of the DCF Model 2.0 by financial analysts.

\section{Illustration}

Table 1 presents an illustration where a firm's assets will generate cash flows for four years only whether it operates on a stand-alone basis or merged with any of three potential acquirers A, B and C. For further simplicity, assume that cash flows are paid at yearend, that cash flows are presented net of integration costs and of cannibalistic effects on acquirers' projected cash flows, that potential acquisitions would have no effect on the present value of debt, that the $r$ presented for acquirers are optimal on a post-merger pro forma basis, that assets have no residual value, and finally that assets cannot be sold back and forth between potential acquirers nor spun-off once acquired.

In this illustration, the traditional DCF valuation model (Equation (1)) would suggest a fair value of $\$ 65.61$ for the stand-alone firm. Under certainty of acquisition, Equation (2) suggests a Value $_{(2)}^{2.0}$ of $\$ 87.56$, which would justify a takeover premium of up to $33.5 \%$ over a market price based on the traditional valuation. In this illustration, both Firm A and Firm B would be rational acquirers.

If assets could be sold back and forth between potential acquirers or spun off once acquired, Equation (3) would produce a firm Value $\mathbf{C}_{(3)}^{2.0}$ of $\$ 105.95$ as the assets are merged with those of Firm A in year 1, then Firm B in year 2, Firm C in year 3 and back to Firm B in year 4.

If we assign a probability of acquisition (conditional upon the acquisition being expectedly profitable) in all periods equal to $70 \%$ for Firm A, $80 \%$ for Firm B, and 90\% for Firm C, Equation (4) yields an expected Value $_{(4)}^{2.0}$ of $\$ 83.17$ and Equation (5) an expected $\operatorname{Value}_{(5)}^{2.0}$ of $\$ 99.41$. With probabilities lowered to $50 \%$, $60 \%$ and $70 \%$, expected values would be lower at $\$ 78.78$ and $\$ 91.35$, respectively.

\section{Implications}

In addition to raising awareness about the importance of the synergetic potential of a firm's assets, DCF Model 2.0 provides a framework to assess and quantify two valuation principles that may have been intuitively ap- 
Table 1. Illustrative example.

\begin{tabular}{ccccc}
\hline & Stand-Alone Firm & Merger with Firm A & Merger with Firm B & Merger with Firm C \\
\hline Net CF1 & $\$ 50$ & $\$ 50$ & $\$ 40$ & $\$ 50$ \\
Net CF2 & $\$ 50$ & $\$ 50$ & $\$ 60$ & $\$ 55$ \\
Net CF3 & $\$ 50$ & $\$ 50$ & $\$ 60$ & $\$ 85$ \\
Net CF4 & $\$ 50$ & $\$ 50$ & $\$ 100$ & $\$ 100$ \\
Market Value of Debt & $\$ 100$ & $6 \%$ & $\$ \%$ & $15 \%$ \\
$r$ & $8 \%$ & $\$ 73.26$ & $\$ 87.56$ & $\$ 63.83$ \\
Present Value of Net Future CF & $\$ 65.61$ & $11.7 \%$ & $33.5 \%$ & $-2.7 \%$ \\
Premium vs. Traditional Model & --- & & $\$ 100$ \\
\hline
\end{tabular}

pealing. First, a firm that remains marketable after it has been acquired has a value greater than, or equal to, a similar firm whose operations must be integrated permanently and "destructively" into the operations of its acquirer to deploy synergies (i.e., Value $e_{(5)}^{2.0} \geq \operatorname{Value}_{(4)}^{2.0}$ ). Second, a firm that is more likely to be acquired has a value greater than, or equal to, a similar firm less likely to be acquired because both Value ${ }_{(4)}^{2.0} \cdot 0$ and Value ${ }_{(5)}^{2.0} \cdot 0$ are monotonically non-decreasing as $P[A]$ increases.

DCF Model 2.0 consequently implies that a comprehensive analysis of a firm's competitive environment, especially its potential fit as a potential target for acquisition, may lead to more accurate valuations and less surprising acquisition premiums.

\section{REFERENCES}

[1] P. Fernandez, "Valuing Companies by Cash Flow Discounting: Ten Methods and Nine Theories," Managerial Finance, Vol. 33, No. 11, 2007, pp. 853-876. http://dx.doi.org/10.1108/03074350710823827

[2] G. I. White, A. C. Sondhi and D. Fried, "The Analysis and Use of Financial Statements," 3rd Edition, 2003, Wiley, New York. 